\title{
Up-regulated expression of type II very low density lipoprotein receptor correlates with cancer metastasis and has a potential link to $\beta$-catenin in different cancers
}

\author{
Lei He${ }^{1}$, Yanjun Lu², Peng Wang ${ }^{1}$, Jun Zhang ${ }^{3}$, Chuanchang Yin ${ }^{4}$, Shen $\mathrm{Qu}^{1 *}$
}

\begin{abstract}
Background: Very low density lipoprotein receptor (VLDLR) has been considered as a multiple function receptor due to binding numerous ligands, causing endocytosis and regulating cellular signaling. Our group previously reported that enhanced activity of type II VLDLR (VLDLR II), one subtype of VLDLR, promotes adenocarcinoma SGC7901 cells proliferation and migration. The aim of this study is to explore the expression levels of VLDLR II in human gastric, breast and lung cancer tissues, and to investigate its relationship with clinical characteristics and $\beta$-catenin expression status.
\end{abstract}

Methods: VLDLR II expression was examined using immunohistochemistry (IHC) and Western blot in tumor tissues from 213 gastric, breast and lung cancer patients, tumor adjacent noncancerous tissues by same methods. Correlations between VLDLR II and clinical features, as well as $\beta$-catenin expression status were evaluated by statistical analysis.

Results: The immunohistochemical staining of VLDLR II showed statistical difference between tumor tissues and tumor adjacent noncancerous tissues in gastric, breast and lung cancers ( $P=0.034,0.018$ and 0.043 , respectively). Moreover, using Western, we found higher VLDLR II expression levels were associated with lymph node and distant metastasis in gastric and breast cancer $(P<0.05)$. Furthermore, highly significant positive correlations were found between VLDLR II and $\beta$-catenin in gastric cancer $(r=0.689$; $P<0.001)$ breast cancer $(r=0.594 ; P<0.001)$.

Conclusions: According to the results of the current study, high VLDLR II expression is correlated with lymph node and distant metastasis in gastric and breast cancer patients, the data suggest that VLDLR II may be a clinical marker in cancers, and has a potential link with $\beta$-catenin signaling pathway. This is the first to reveal the closer relationship of VLDLR II with clinical information.

\section{Background}

The very low density lipoprotein receptor (VLDLR) which belongs to the low density lipoprotein receptor (LDLR) family was initially cloned on the basis of its homology to the LDLR [1]. This receptor exhibits domain structures similar to those of the LDLR, except it has an extra repeat of the cysteine-rich ligand-binding domain. The tissue distribution of VLDLR is most abundantly expressed in heart,

\footnotetext{
* Correspondence: qs_cn@sina.com

'Department of Biochemistry and Molecular Biology, Tongji Medical College, Huazhong University of Science and Technology, Wuhan 430030, China Full list of author information is available at the end of the article
}

skeletal muscle and adipose tissue [2], the VLDLR is originally considered to specifically bind to VLDL and played important roles for apolipoprotein $\mathrm{E}$ (apoE) metabolism. Interest in VLDLR has focused mainly on its possible role in extrahepatic tissues active in fatty acid metabolism and its role as an energy source [3]. However, the physiological and pathological importance of this receptor has not been clearly identified. Previous studies has found that VLDLR is a multiple function receptor due to binding numerous ligands besides lipoproteins, including lipoprotein lipase (LPL), receptor-associated protein (RAP), thrombospondin-1, urokinase plasminogen activator/plasminogen
Ciomed Central 
activator inhibitor-1 complex (uPA/PAI-1) and several other proteinase-serpin complexes, causing endocytosis and affecting many cellular functions [4-8].

Furthermore, a signaling function for the VLDLR has also been recognized, as demonstrated by the ability of reelin to modulate neuronal migration, neurodevelopment, and other physiological processes in the central nervous system. Binding of reelin to VLDLR induces tyrosine phosphorylation of Disable-1 (Dab-1) in neurons [9]. In addition to neuronal migration via reelin, in vitro studies revealed that the VLDLR modulates cell migration via a pathway that depends on uPA [10]. That receptor-bound $\mathrm{UPA}$ plays a pivotal role in tumor invasion and metastasis via the generation of plasmin and subsequent degradation of the extracellular matrix in various processes like cancer cell invasion, stromal remodelling, and angiogenesis [11]. So the VLDLR appears to regulate biological processes by binding or internalization of ligands, or by transducing extracellular signals across the cell membrane.

VLDLR consists of two subtypes because of alternative splicing, namely the full-length VLDLR and type II VLDLR (VLDLR II) which lacks the O-linked sugar domain encode by the 16th exon. The tissue distribution of two VLDLR subtypes are different, the full-length VLDLR mainly expressed in heart and muscles with high lipid metabolism, whereas VLDLR II is a 105 $\mathrm{kDa}$ protein that mainly expressed in kidney, spleen, adrenal gland and testis [12]. The previous research has also shown that VLDLR II is predominantly expressed in the gastroenterological cancer, breast cancer, lung cancer and so on [13]. Other report indicates that the O-linked sugar domain of VLDLR has been demonstrated to be responsible for cell growth inhibition, and this growth inhibition is ligand-independed [14]. These studies suggest that VLDLR II activities may be related to certain cellular functions other than its involvement in lipoprotein metabolism, and has been speculated to promote the tumor cells to proliferate and metastasis.

$\beta$-catenin is part of the cadherin-catenin complex that mediates cell-cell adhesion [15] and is a critical member of the canonical Wnt signaling pathway that is active normally in embryogenesis. It also is believed that aberrant Wnt signaling is a characteristic shared by numerous human tumors [16]. Recent studies have revealed that Wnt signal transduction plays a pivotal role in human tumor development, where it mediates the transcription of numerous downstream target genes associated with increased growth and invasion [17]. Chen et al reported that VLDLR is a negative regulator of the Wnt signaling pathway [18]. But in the past research, we have indicated that increased $\beta$-catenin accumulation is found in the human gastric adenocarcinoma cell line SGC7901, accompanied by an increase in VLDLR II expression.
These previous results suggest that the molecular mechanism underlying the role of VLDLR II in tumor cell proliferation and migration may be related to the stability of $\beta$-catenin and the subsequent activation of the transcription of certain target genes. However, in tumor tissue levels, whether the mount of $\beta$-catenin has a correlation with VLDLR II expression need to be elucidated.

In the current study, we examined the expression of VLDLR II in different carcinoma samples by immunohistochemistry (IHC) and Western blot, and investigated whether the expression of VLDLR II are different between normal and malignant tissues. Then we further analyzed potential correlations of VLDLR II expression levels with various clinicopathologic tumor features, as well as with $\beta$-catenin expression levels.

\section{Methods}

\section{Clinical cancer specimens}

213 clinical specimens from gastric, breast and lung cancer patients who had undergone surgical resection (starting from 2008) at the department of surgery, both of Tongji Hospital and Union Hospital (Wuhan, China), were investigated in this study. Informed consent was obtained from patients for their tissues to be used in research. For each patient, a sample of adjacent and apparently non-affected tissue was also taken and used as normal control. The histological diagnosis of each tumor was confirmed on the hematoxylin and eosin-stained sections. Pathologic tumor, lymph node, metastasis (TNM) status were assessed in all patients according to the TNM classification system of the International Union Against Cancer/American Joint Committee on Cancer (UICC/ AJCC). In order to ensure reliable results, we divided above-mentioned cancer samples into two groups, one group was comprised of 22 gastric cancers, 18 breast cancers, and 24 lung cancers, they were fixed in formalin and embedded in paraffin for IHC. Another group also consists of surgical specimens of gastric, breast, and lung cancers $(52,46,51$, respectively), and were snap-frozen immediately after resection using liquid nitrogen and stored at $-80^{\circ} \mathrm{C}$ until used for Western blot analysis. The choice and grouping of all samples were based on blind election and random principle. All patients gave informed consent to use excess pathological specimens for research purposes. Research was carried out in compliance with Helsinki Declaration with the approval of the Ethics Committee of Tongji Medical College (Email: tongjilunli@163.com).

\section{Antibodies}

The monoclonal antibody against VLDLR II was prepared as previously described [19], which could be applied for IHC and Western blot examination. The mouse monoclonal anti-human $\beta$-catenin was obtained 
from R\&D systems, Minneapolis (MN, USA). The antibody against $\beta$-actin was purchased from Santa Cruz Biotechnology (CA, USA).

\section{Immunohistochemistry methods}

Antibody staining was performed on 4- $\mu \mathrm{m}$ histological sections of formalin-fixed, paraffin-embedded tumor and adjacent normal samples. Serial $4-\mu$ m sections were mounted on pretreated glass slides, deparaffinized, rehydrated, and microwaved for 15 minutes at high power in $10 \mathrm{mmol} / \mathrm{L}$ citrate buffer ( $\mathrm{pH}$ 6.0) to unmask the epitopes. Endogenous peroxidase was quenched using $3 \%$ $\mathrm{H}_{2} \mathrm{O}_{2}$ for 10 minutes; slides were then washed in phosphate-buffered saline (PBS, pH 7.5) and incubated with the $5 \%$ bovine serum albumin (BSA) for 20 minutes. Sections were incubated overnight at $4^{\circ} \mathrm{C}$ with a $1: 100$ dilution of anti-VLDLR II antibody described above. After washing, the sections were incubated with horseradish peroxidase-conjugated secondary antibodies for 1 hour at room temperature. After washing, tissues were stained for 5 minutes with DAB (3, 3'-diaminobenzidine) chromogen and counterstained with hematoxylin, dehydrated, and coverslipped. Each experiment was performed in duplicate. Mean values from repeated counts were recorded for each case.

\section{Evaluation of immunohistochemistry}

For each spot, areas of most intense and/or predominant staining pattern were scored by eye. Immunostaining pattern for each case was independently evaluated by two investigators (YJL and PW) at a two-headed microscope. VLDLR II expression was classified according to the following grading system: staining intensity was categorized as 0 (negative), 1 (weak), 2 (moderate), or 3 (strong). Staining areas were categorized as 0 (no positive cells), 0.1 ( $\leq 25 \%$ positive cells), 0.4 ( $>25 \%$ and $\leq 50 \%$ positive cells), 0.6 (> 50\% and $\leq 75 \%$ positive cells), or 0.9 (> 75\% positive cells). To gauge both stain intensity and uniformity simultaneously, the average values for intensity for each tissue were multiplied by the average values for percentage area stained in each tissue to derive a composite histoscore (i.e., histoscore $=$ area $\times$ intensity). A tissue with intense, uniform staining would be assigned the maximum histoscore of 2.7 , whereas a tissue with light staining intensity (a value of 1 ) in only $>25 \%$ and $\leq 50 \%$ of the tissue (a value of 0.4) would get a histoscore of 0.4 . Assigning a histoscore is now a commonly used method for evaluating both stain uniformity and intensity in tissues to better relate results between multiple samples from immunohistochemical studies [20].

\section{Western blot analysis}

Prior to immunoblotting, tissues were washed three times with ice cold PBS, homogenized in lysis buffer
(1\% NP-40, $50 \mathrm{mmol} / \mathrm{L}$ Tris, pH 7.5, $5 \mathrm{mmol} / \mathrm{L}$ EDTA, $1 \%$ SDS, $1 \%$ sodium deoxycholate, $1 \%$ Triton $\mathrm{X}-100,1$ $\mathrm{mmol} / \mathrm{L}$ PMSF, $10 \mathrm{mg} / \mathrm{mL}$ aprotinin, and $1 \mathrm{mg} / \mathrm{mL}$ leupeptin) and then incubated for 20 minutes at $4{ }^{\circ} \mathrm{C}$ while rocking. Lysates were cleared by centrifugation (10 min, $12000 \mathrm{rpm}, 4^{\circ} \mathrm{C}$ ). $100 \mu \mathrm{g}$ of total protein was resolved by $10 \%$ SDS-PAGE and transferred onto nitrocellulose membranes (Immbilon, Millipore). The membranes were blocked with 5\% nonfat dry milk for 2 hours at room temperature, and then incubated overnight at $4^{\circ} \mathrm{C}$ with first antibodies which were against VLDLR II, $\beta$-actin or $\beta$-catenin. After washing the membranes 3 times with TBST $(50 \mathrm{mmol} / \mathrm{L}$ Tris-HCL pH7.6, $150 \mathrm{mmol} / \mathrm{L} \mathrm{NaCl}, 0.1 \%$ Tween 20), membranes were incubated with horseradish peroxidase-conjugated secondary antibodies for 1 hour at room temperature according to the manufacturer's instructions. The membranes were washed 3 times with TBST. Detection of immunocomplexes was performed with an enhanced chemiluminescence system (NEN Life Science Products, Boston, MA), the values were normalized to $\beta$-actin expression, and the level of protein expression determined using Image Quant TL software (Amersham Pharmacia Biotech, Piscataway, USA).

\section{Statistical analysis}

The difference of VLDLR II expression between tumor and paired normal tissues were assessed using the student $t$-test for paired values, both IHC and Western blot data were used to establish this diversities. The MannWhitney test or Kruskal-Wallis test (for $>2$ groups) were used to analyze the association between expression levels of VLDLR II and clinical parameters. The direction and the strength of association between VLDLR II and $\beta$-catenin were evaluated and compared with the Spearman correlations test. Data were reported as mean $\pm \mathrm{SD}, P$ value $<0.05$ was considered statistically significant. All statistical analyses were performed with Superior Performance Software System (SPSS) 15.0 for Windows (SPSS Inc, Chicago, IL).

\section{Results}

\section{Detection of cellular VLDLR II expression by IHC staining of cancer tissues}

Using IHC, we examined the distribution of VLDLR II protein in parraffin-embedded mammary tissue sections screened from gastric, breast and lung cancer patients (22, 18, and 24, respectively). VLDLR II was mainly localized in the cytomembrane of either tumor or normal cell (Figure 1). Here, the level of VLDLR II expression refers to the histoscore of cells within each tissue sample that stained positively for the special antibody, and the evaluation scoring system had been described 

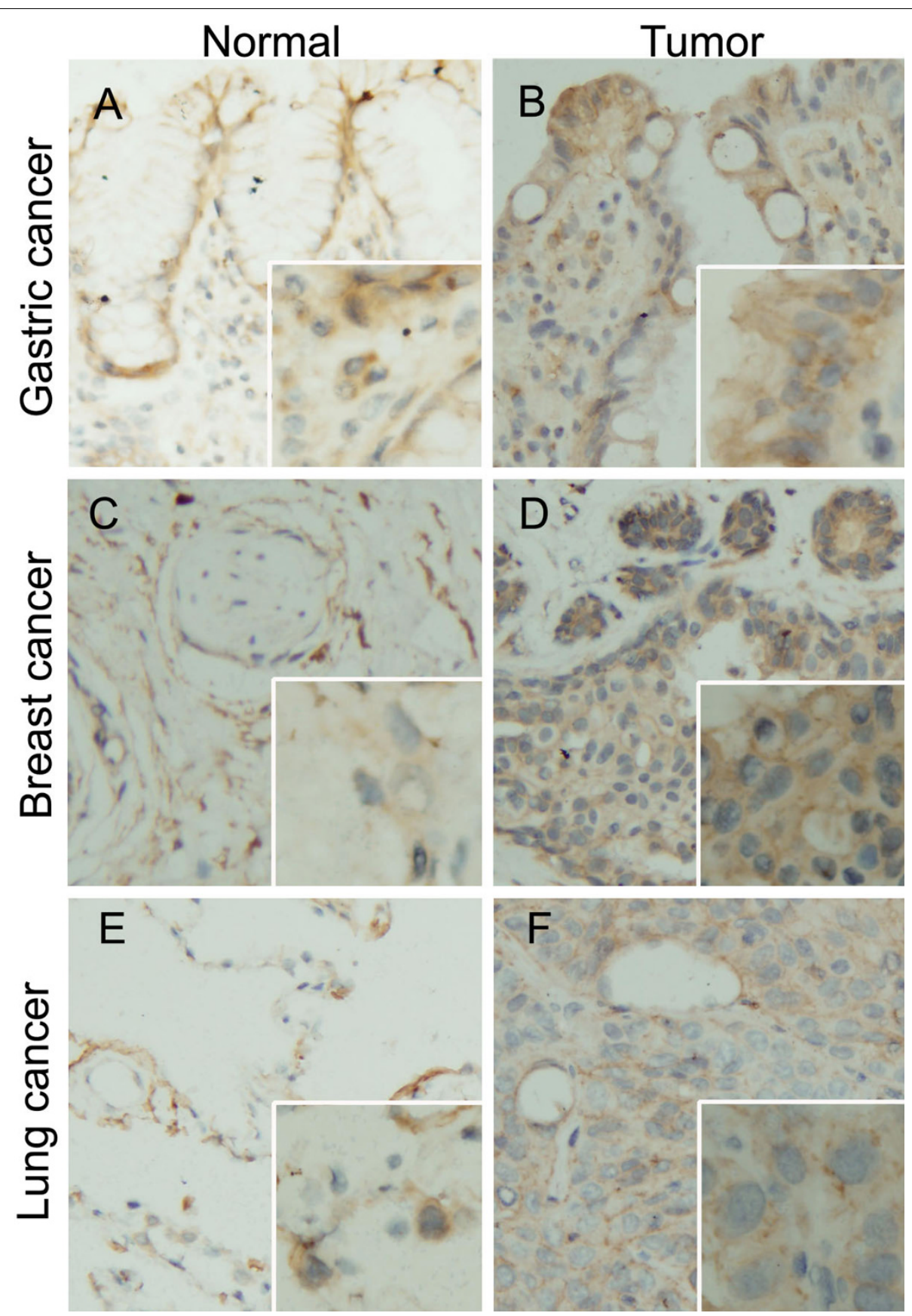

Figure 1 VLDLR II detection by IHC. Representative Immunohistochemical staining of VLDLR II protein in paraffin-embedded human different cancers and matched adjacent noncancerous tissues. A, B: Gastric normal and tumor tissue; C, D: Breast normal and tumor tissue; E, F: Lung normal and tumor tissue. VLDLR II staining show predominantly membranous localization, and a much smaller subset also showed cytoplasmic staining. Normal tissues seen in A, C, E are weak-to-moderate stained, while in cancer cells, VLDLR II staining are strongly intense (B, D, F). Original magnification: $\times 200 ; \times 400$ (insets).

above. The cells with brown staining were considered positively stained, and their percentage within the tissue was determined. Comparison between tumor and normal tissue revealed that VLDLR II expression levels were significantly increased in gastric, breast and lung cancer patients $(P=0.034,0.018$, and 0.043 , respectively;
Figure 2). Moreover, we observed a tissue specific profile of VLDLR II protein expression both in tumor and normal tissues, with highest levels of expression in breast cancer, followed by gastric and lung cancer. The histoscore of VLDLR II staining from different cancers were summarized in Table 1. 


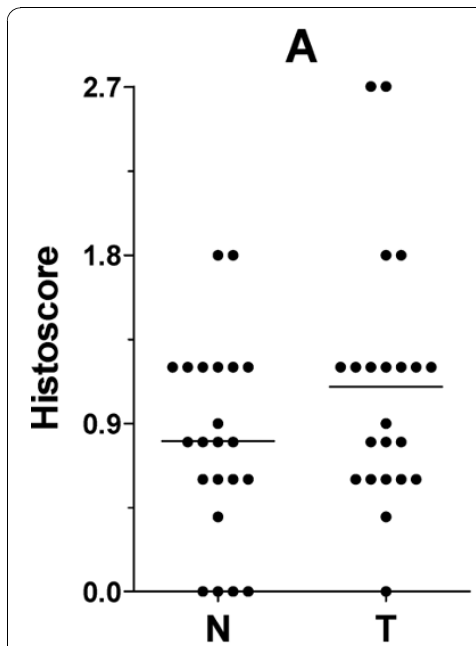

Gastric cancer
B

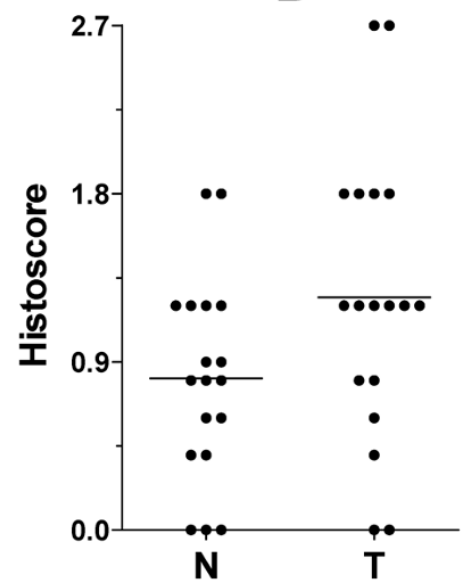

Breast cancer

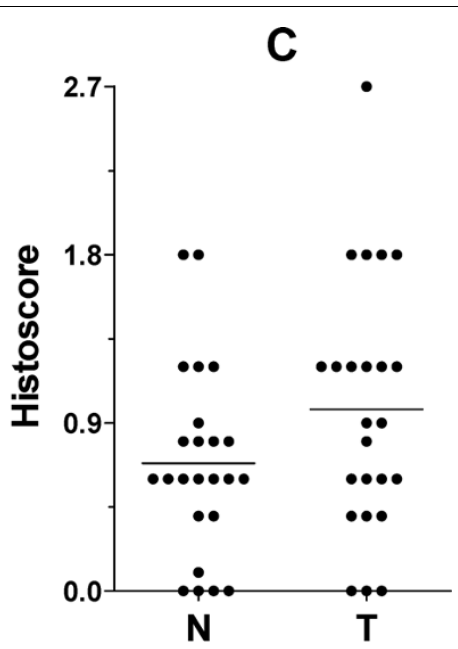

Lung cancer

Figure 2 The histoscore of VLDLR II staining in gastric (A), breast (B), lung (C) cancers and in the paired non-affected ones. Statistical analysis with histoscore (area stained multiplied by intensity) of VLDLR II in tissues from gastric, breast and lung cancer patients (22, 18, and 24, respectively). VLDLR II expression levels are significantly higher in tumors compared with normal tissues $(P=0.034,0.018$, and 0.043 , respectively). Abbreviations: N, matched adjacent normal tissue; T, tumor tissue.

\section{Expression of VLDLR II protein by Western blot in difference cancer tissues}

In order to verify the IHC results and further assess VLDLR II expression whether correlates with clinical information, the cancer specimens and paired noninfected tissues from gastric, breast and lung cancer patients (52, 46 and 51, respectively) were analyzed by Western blot to quantitatively assess the proteins investigated. The values were normalized to $\beta$-actin expression. As shown in Table 1, VLDLR II was detected in cancer tissues at significantly higher levels than in the normal tissues from gastric and breast cancers $(P=$ $0.003,0.001)$, both results paralleled IHC data. But no

Table 1 Expression of VLDLR II in different cancers

\begin{tabular}{|c|c|c|c|c|c|c|c|c|}
\hline & \multicolumn{4}{|c|}{$\begin{array}{l}\text { IHC } \\
\text { (Histoscore of VLDLR } \\
\text { II) }\end{array}$} & \multicolumn{4}{|c|}{$\begin{array}{c}\text { Western blot } \\
\text { (Ratio of VLDLR II/ } \beta \text { - } \\
\text { actin) }\end{array}$} \\
\hline & $\mathbf{N}$ & mean & SD. & $P$ & $\mathbf{N}$ & Mean & SD. & $P$ \\
\hline Gastric cancer & 22 & & & & 52 & & & \\
\hline Normal tissue & 22 & 0.80 & 0.67 & $0.034^{*}$ & 52 & 0.78 & 0.26 & $0.003^{*}$ \\
\hline Cancer tissue & 22 & 1.10 & 0.53 & & 52 & 0.93 & 0.40 & \\
\hline Breast cancer & 18 & & & & 46 & & & \\
\hline Normal tissue & 18 & 0.81 & 0.54 & $0.018^{*}$ & 46 & 0.93 & 0.43 & $0.001^{*}$ \\
\hline Cancer tissue & 18 & 1.24 & 0.77 & & 46 & 1.10 & 0.48 & \\
\hline Lung cancer & 24 & & & & 51 & & & \\
\hline Normal tissue & 24 & 0.68 & 0.50 & $0.043^{*}$ & 51 & 0.57 & 0.19 & 0.073 \\
\hline Cancer tissue & 24 & 0.97 & 0.67 & & 51 & 0.61 & 0.21 & \\
\hline
\end{tabular}

Statistical analyses were performed by Paired Students' $t$ test (2-tailed). * $P<0.05$ is considered significant. significant differences were found in lung caners $(P=$ 0.073).

\section{VLDLR II protein in gastric cancer tissues}

We assessed the expression level of VLDLR II in gastric cancer tissues and matched adjacent normal tissues via Western blot analysis. Figure 3A illustrated VLDLR II expression in 8 representative gastric cancer patients. Through statistical analysis with relative protein expression levels of VLDLR II in gastric cancer tissues from 52 patients, as shown in box graph, we found that VLDLR II expression was significantly elevated in gastric cancers in comparison to the matched normal adjacent tissues, this result was consistent with which obtained via IHC. In addition, VLDLR II expression in cancer tissues was not significantly associated with age, gender, tumor size or histological grade. But elevated VLDLR II expression was associated with lymph node metastasis $(P=0.013)$ and a higher expression was noted in patients with distant metastasis $(P=0.004)$ and advanced TNM stage group $(P=0.011)$. Because VLDLR II played role for lipid metabolism, we also analysed the relationship between VLDLR II expression and other clinical features including body weight and plasma lipid profiles. The results shown that VLDLR II expression in cancer tissues was not significantly associated with body weight, total cholesterol (TC) and triglycerides (TG) (Table 2).

\section{VLDLR II protein in breast cancer tissues}

We classified 46 patients with breast cancer, according to the TNM stage, histological grade, plasma lipid profiles and the levels of total VLDLR II protein in each subgroup. Significant increases in VLDLR II protein 


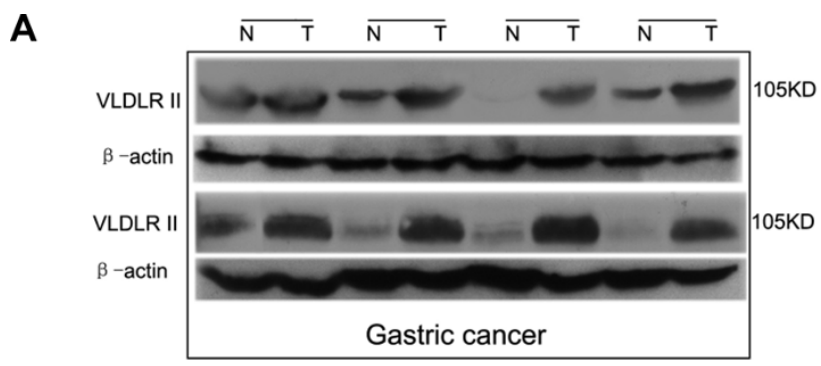

B

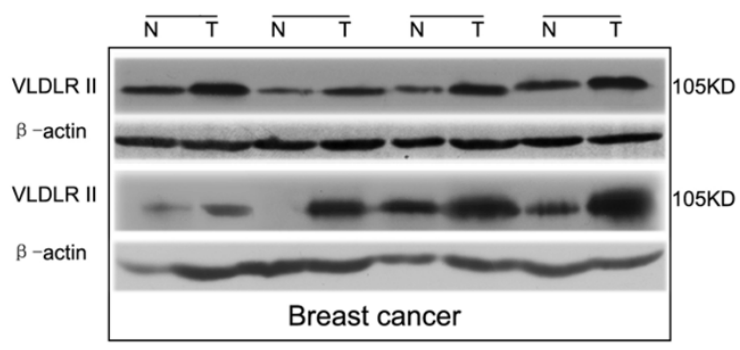

C

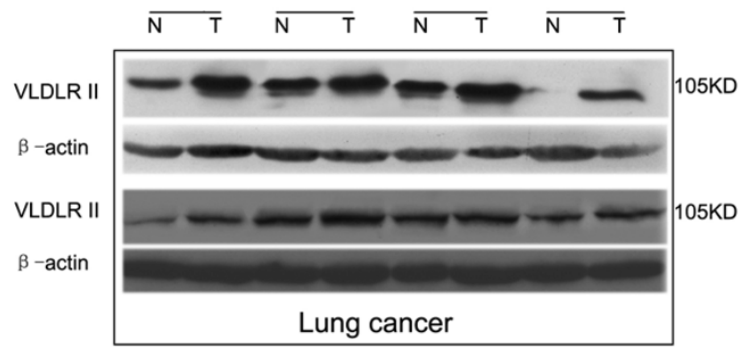

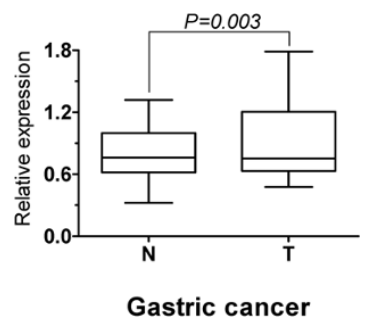
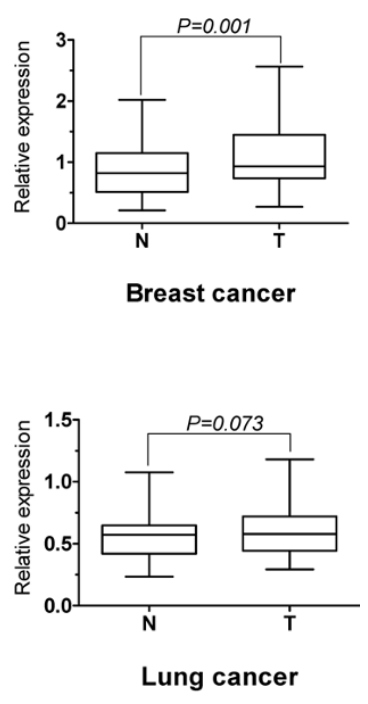

Figure 3 Western blot analysis of VLDLR II expression from normal and tumor samples. $100 \mu \mathrm{g}$ of total protein extracted from tumor tissues and matched adjacent noncancerous tissues were tested by Western blot. A-C: Some representative samples from gastric, breast, and lung cancer patients (8 for each), indicate as $\mathrm{N}$ and T for normal and tumor samples. VLDLR II expression levels are higher in gastric and breast tumor tissues compared with matched adjacent noncancerous tissues (A, B). In lung tumor tissues, VLDLR II is either high or similar as compared with normal tissues (C). The same filter membranes were probed with $\beta$-actin. The bands were densitometrically scanned and referred to $\beta$-actin as internal control. The box graphs are shown the statistical analysis with relative protein expression levels of VLDLR II in tissues from gastric, breast, and lung cancer patients (52, 46, and 51, respectively). Abbreviations: $\mathrm{N}$, normal tissue; T, tumor tissue.

were observed in tumor group of the breast cancer patients studied (Figure 3B). As shown in Table 3, not only a global increase of VLDLR II in cancer tissues in comparison to their paired adjacent non-affected tissue, but also the higher expression of VLDLR II is associated with lymph node metastasis, distant metastasis and poorly differentiated ( $P=0.003,0.007$ and 0.043 , respectively). With regard to TNM stage, the difference is statistically significant with stage III-IV group and stag I-II group $(P=0.027)$, whereas in age, body weight, TC, TG, and tumor size, it was not.

\section{VLDLR II protein in lung cancer tissues}

In a group of 51 patients affected by lung cancer, as shown in Figure 3C, the comparison between normal and cancer tissues did not indicate significant difference in expression of VLDLR II protein, this result was different with which obtained via IHC (Table 1). However, to gain better insight into the expression level of VLDLR II in histological types of lung cancer, we analysed the difference expression of VLDLR II between normal and cancer tissues in 4 histological types of lung cancer (18 adenocarcinomas, 24 squamous carcinomas, 6 small cell lung carcinomas, and 3 adeno-squamous carcinomas). The expression of VLDLR II was significantly elevated in adenocarcinoma tissues in comparison to the corresponding adjacent non-affected tissues $(P=0.048)$, whereas in other histological types, it was not (Table 4). When analyzing expression levels of VLDLR II associated with common clinical features, we found the difference was statistically significant only in patients with distant metastasis $(P=0.008)$. Clinical variables were summarized in Table 5 .

\section{Correlation between VLDLR II protein and $\beta$-catenin expression levels in different cancers}

In previous study, we had found that increased $\beta$-catenin accumulated in the SGC7901 cell line, accompanied by 
Table 2 Correlation between VLDLR II expression and clinical features in $\mathbf{5 2}$ gastric cancer patients

\begin{tabular}{|c|c|c|c|}
\hline Parameters & Number & VLDLR II fold & $P$ \\
\hline \multicolumn{4}{|l|}{ Age at diagnosis } \\
\hline$\geq 60$ years & 26 & $1.34 \pm 0.58$ & 0.133 \\
\hline$<60$ years & 26 & $1.19 \pm 0.55$ & \\
\hline \multicolumn{4}{|l|}{ Gender } \\
\hline Male & 37 & $1.28 \pm 0.58$ & 0.709 \\
\hline Female & 15 & $1.22 \pm 0.55$ & \\
\hline \multicolumn{4}{|l|}{ Body weight } \\
\hline$\geq 60 \mathrm{~kg}$ & 17 & $1.14 \pm 0.31$ & 0.565 \\
\hline$<60$ kg & 35 & $1.33 \pm 0.65$ & \\
\hline \multicolumn{4}{|l|}{ TC } \\
\hline$>5.20 \mathrm{mmol} / \mathrm{L}$ & 11 & $1.11 \pm 0.20$ & 0.662 \\
\hline$\leq 5.20 \mathrm{mmol} / \mathrm{L}$ & 41 & $1.31 \pm 0.62$ & \\
\hline \multicolumn{4}{|l|}{ TG } \\
\hline$>1.70 \mathrm{mmol} / \mathrm{L}$ & 9 & $1.02 \pm 0.23$ & 0.204 \\
\hline$\leq 1.70 \mathrm{mmol} / \mathrm{L}$ & 43 & $1.32 \pm 0.60$ & \\
\hline \multicolumn{4}{|l|}{ Histological grade } \\
\hline Well to moderately differentiated & 30 & $1.19 \pm 0.55$ & 0.165 \\
\hline Poorly differentiated & 22 & $1.37 \pm 0.58$ & \\
\hline \multicolumn{4}{|l|}{ Tumor size } \\
\hline$\geq 5 \mathrm{~cm}$ & 25 & $1.40 \pm 0.60$ & 0.087 \\
\hline$<5 \mathrm{~cm}$ & 27 & $1.14 \pm 0.51$ & \\
\hline \multicolumn{4}{|l|}{ Lymph node metastasis } \\
\hline Negative & 15 & $1.02 \pm 0.51$ & $0.013^{*}$ \\
\hline Positive & 37 & $1.35 \pm 0.56$ & \\
\hline \multicolumn{4}{|l|}{ Distant metastasis } \\
\hline Negative & 41 & $1.13 \pm 0.41$ & $0.004^{*}$ \\
\hline Positive & 11 & $1.78 \pm 0.77$ & \\
\hline \multicolumn{4}{|l|}{ TNM stage } \\
\hline Stage $|-| \mid$ & 22 & $1.08 \pm 0.46$ & $0.011^{*}$ \\
\hline Stage III-IV & 30 & $1.40 \pm 0.60$ & \\
\hline
\end{tabular}

Folds (VLDLR II protein in tumor/in normal) in mean \pm SD, VLDLR II measured by Western blot. TC, total cholesterol (normal range: $\leq 5.20 \mathrm{mmol} / \mathrm{L}$ ); TG, triglycerides (normal range: $\leq 1.70 \mathrm{mmol} / \mathrm{L}$ ). Statistical analyses were performed by Mann-Whitney test.

* $P<0.05$ is considered significant.

an increase in VLDLR II expression [21]. In current study, we further examined whether the VLDLR II expression could be correlated with $\beta$-catenin in tissue levels from different cancers. Except for evaluating VLDLR II expression in different cancer tissues, we also detected $\beta$-catenin in same cancer specimens and adjacent normal tissues by Western blot. $\beta$-catenin expression levels were different between normal and tumor tissues from gastric, breast, and lung cancer patients (Figure 4A). Next, we evaluated the correlation between VLDLR II and $\beta$-catenin expression, as a result, Figure $4 \mathrm{~B}$ and $4 \mathrm{C}$ illustrated that highly significant positive correlations were found between VLDLR II and $\beta$-catenin in gastric cancers (Spearman test: $r=0.689 ; P<0.001$ ) and breast cancers (Spearman test: $r=0.594 ; P<0.001$ ),
Table 3 Correlation between VLDLR II expression and clinical features in 46 Breast cancer patients

\begin{tabular}{|c|c|c|c|}
\hline Parameters & Number & VLDLR II fold & $P$ \\
\hline \multicolumn{4}{|l|}{ Age at diagnosis } \\
\hline$\geq 50$ years & 29 & $1.30 \pm 0.44$ & 0.820 \\
\hline$<50$ years & 17 & $1.28 \pm 0.40$ & \\
\hline \multicolumn{4}{|l|}{ Body weight } \\
\hline$\geq 50 \mathrm{~kg}$ & 19 & $1.38 \pm 0.39$ & 0.080 \\
\hline$<50 \mathrm{~kg}$ & 27 & $1.21 \pm 0.43$ & \\
\hline \multicolumn{4}{|l|}{ TC } \\
\hline$>5.20 \mathrm{mmol} / \mathrm{L}$ & 7 & $1.09 \pm 0.34$ & 0.178 \\
\hline$\leq 5.20 \mathrm{mmol} / \mathrm{L}$ & 39 & $1.31 \pm 0.42$ & \\
\hline \multicolumn{4}{|l|}{ TG } \\
\hline$>1.70 \mathrm{mmol} / \mathrm{L}$ & 13 & $1.15 \pm 0.28$ & 0.360 \\
\hline$\leq 1.70 \mathrm{mmol} / \mathrm{L}$ & 33 & $1.33 \pm 0.45$ & \\
\hline \multicolumn{4}{|l|}{ Histological grade } \\
\hline Well to moderately differentiated & 28 & $1.18 \pm 0.36$ & $0.043^{*}$ \\
\hline Poorly differentiated & 18 & $1.43 \pm 0.45$ & \\
\hline \multicolumn{4}{|l|}{ Tumor size } \\
\hline$\geq 2 \mathrm{~cm}$ & 21 & $1.34 \pm 0.47$ & 0.442 \\
\hline$<2 \mathrm{~cm}$ & 25 & $1.22 \pm 0.37$ & \\
\hline \multicolumn{4}{|l|}{ Lymph node metastasis } \\
\hline Negative & 15 & $1.14 \pm 0.15$ & $0.003^{*}$ \\
\hline Positive & 31 & $1.43 \pm 0.45$ & \\
\hline \multicolumn{4}{|l|}{ Distant metastasis } \\
\hline Negative & 32 & $1.16 \pm 0.30$ & $0.007^{*}$ \\
\hline Positive & 14 & $1.52 \pm 0.41$ & \\
\hline \multicolumn{4}{|l|}{ TNM stage } \\
\hline Stage I-II & 24 & $1.14 \pm 0.31$ & $0.027^{*}$ \\
\hline Stage III-IV & 22 & $1.41 \pm 0.47$ & \\
\hline
\end{tabular}

Folds (VLDLR II protein in tumor/in normal) in mean \pm SD. VLDLR II measured by Western blot. TC, total cholesterol (normal range: $\leq 5.20 \mathrm{mmol} / \mathrm{L}$ ); TG, triglycerides (normal range: $\leq 1.70 \mathrm{mmol} / \mathrm{L}$ ). Statistical analyses were performed by Mann-Whitney test.

${ }^{*} P<0.05$ is considered significan.

whereas $\beta$-catenin expression didn't correlated with VLDLR II expression in lung cancers (Spearman test: $r=0.222 ; P=0.118$; Figure 4D).

\section{Discussion}

VLDLR is a member of the LDLR family [1], which includes the LDLRs, LDL receptor-related protein (LRP) and so on. These receptors have equivalent structural motifs and band many of same ligands [22]. And now, VLDLR and the other members of LDLR are known as the multifunctional receptor like "Swiss army knife" [23]. It is widely believed that the LDL receptor family participated in the tumorigenesis, which the receptor mediated endocytosis has been as a way to regulate the tumor cell migration [24]. For example, LRP mediates the endocytosis of UPAR through an indirect mechanism that depends on UPA/PAI-1 complex, and then regulates the activity of uPA/uPAR system within cancer cells [25]. Similarly, 
Table 4 Expression of VLDLR II in different histological types of lung cancer

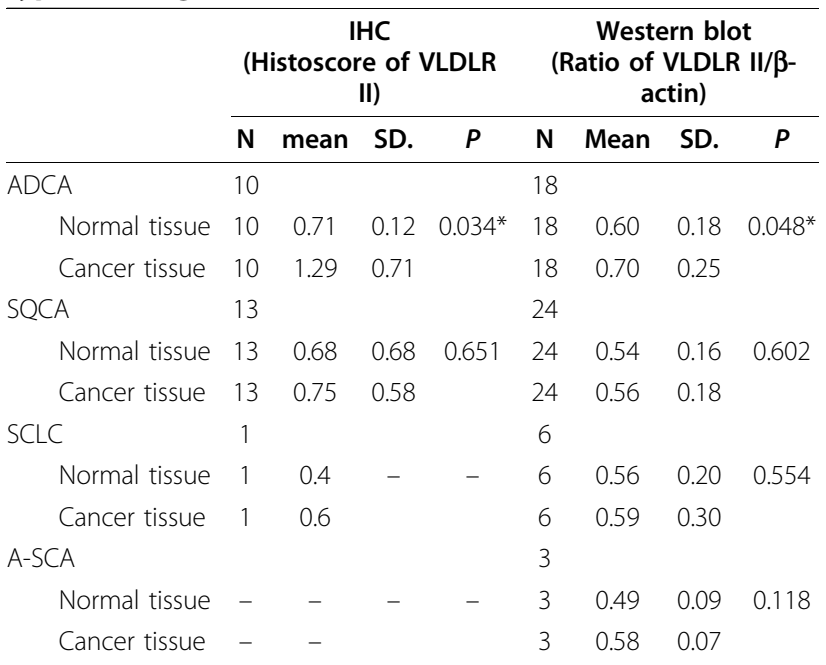

ADCA indicates adenocarcinoma; SQCA, squamous cell carcinoma; SCLC, small cell carcinoma; A-SCA, adeno-squamous carcinoma. Statistical analyses were performed by Paired Students' $t$ test (2-tailed).

$* P<0.05$ is considered significant.

some reports suggested that VLDLR may serve as an energy source for the rapid growth of cancer cells or may function as a modulator for cancer invasion and metastasis through ligands such as uPA and its type1 inhibitor complexes $[7,26]$. Webb et al. reported that VLDLR regulates autocrine uPAR-initiated signaling and thereby regulates MCF-7 breast cancer cell motility [27].

Alternative splicing exists in many members of LDLR family, and there is some supportive evidence in which lipoprotein receptor variants may be involved in different biological processes. In the same way, VLDLR II which lacks the O-linked sugar domain encoded by the 16th exon is emerged through alternative splicing, and mainly expresses in kidney, spleen, adrenal gland and testis. However, the full-length VLDLR is most highly expressed in heart, skeletal muscle and adipose tissue with active fatty acid metabolism [12]. It was generally accepted that full-length VLDLR played an important role in the metabolism of lipoprotein enriched in apoE [1], Wada et al. had indicated that the O-linked sugar domain of VLDLR appeared to be responsible for the cell growth inhibition [14]. Our previous study had found that over-expression of the full-length VLDLR didn't promote SGC7901 cell migration and proliferation, while the cell migration and proliferation were increased in cells stably over-expressing VLDLR II [21]. Another report demonstrated that genetic loss of the VLDLR gene is involved in carcinogenesis including that of gastric carcinogenesis [28]. These studies suggest that VLDLR II activities may be related to certain cellular functions other than its involvement in lipoprotein metabolism.
Table 5 Correlation between VLDLR II expression and clinical features in 51 Lung cancer patients

\begin{tabular}{|c|c|c|c|}
\hline Parameters & Number & VLDLR II fold & $P$ \\
\hline \multicolumn{4}{|l|}{ Age at diagnosis } \\
\hline$\geq 55$ years & 30 & $1.16 \pm 0.25$ & 0.781 \\
\hline$<55$ years & 21 & $1.11 \pm 0.34$ & \\
\hline \multicolumn{4}{|l|}{ Gender } \\
\hline Male & 35 & $1.12 \pm 0.31$ & 0.424 \\
\hline Female & 16 & $1.19 \pm 0.37$ & \\
\hline \multicolumn{4}{|l|}{ Body weight } \\
\hline$\geq 60 \mathrm{~kg}$ & 19 & $1.15 \pm 0.22$ & 0.823 \\
\hline$<60 \mathrm{~kg}$ & 32 & $1.13 \pm 0.32$ & \\
\hline \multicolumn{4}{|l|}{$\mathrm{TC}$} \\
\hline$>5.20 \mathrm{mmol} / \mathrm{L}$ & 12 & $1.03 \pm 0.20$ & 0.096 \\
\hline$\leq 5.20 \mathrm{mmol} / \mathrm{L}$ & 39 & $1.16 \pm 0.30$ & \\
\hline \multicolumn{4}{|l|}{ TG } \\
\hline$>1.70 \mathrm{mmol} / \mathrm{L}$ & 9 & $1.01 \pm 0.35$ & 0.166 \\
\hline$\leq 1.70 \mathrm{mmol} / \mathrm{L}$ & 42 & $1.17 \pm 0.27$ & \\
\hline \multicolumn{4}{|l|}{ Histological grade } \\
\hline Well to moderately differentiated & 38 & $1.11 \pm 0.29$ & 0.133 \\
\hline Poorly differentiated & 13 & $1.25 \pm 0.27$ & \\
\hline \multicolumn{4}{|l|}{ Tumor size } \\
\hline$\geq 5 \mathrm{~cm}$ & 22 & $1.20 \pm 0.30$ & 0.254 \\
\hline$<5 \mathrm{~cm}$ & 29 & $1.09 \pm 0.28$ & \\
\hline \multicolumn{4}{|l|}{ Lymph node metastasis } \\
\hline Negative & 15 & $1.01 \pm 0.37$ & 0.090 \\
\hline Positive & 36 & $1.19 \pm 0.23$ & \\
\hline \multicolumn{4}{|l|}{ Distant metastasis } \\
\hline Negative & 40 & $1.06 \pm 0.26$ & $0.008^{*}$ \\
\hline Positive & 11 & $1.36 \pm 0.29$ & \\
\hline \multicolumn{4}{|l|}{ TNM stage } \\
\hline Stage |-|| & 25 & $1.06 \pm 0.27$ & 0.061 \\
\hline Stage III-IV & 26 & $1.25 \pm 0.29$ & \\
\hline \multicolumn{4}{|l|}{ Histological type } \\
\hline adenocarcinoma & 18 & $1.22 \pm 0.29$ & 0.190 \\
\hline squamous cell carcinoma & 24 & $1.11 \pm 0.31$ & \\
\hline small cell carcinoma & 6 & $1.03 \pm 0.19$ & \\
\hline adeno-squamous carcinoma & 3 & $1.09 \pm 0.07$ & \\
\hline
\end{tabular}

Folds (VLDLR II protein in tumor/in normal) in mean \pm SD. VLDLR II measured by Western blot. TC, total cholesterol (normal range: $\leq 5.20 \mathrm{mmol} / \mathrm{L}$ ); TG, triglycerides (normal range: $\leq 1.70 \mathrm{mmol} / \mathrm{L}$ ). Statistical analyses were performed by Mann-Whitney test (for 2 groups) or Kruskal-Wallis test (for $>2$ groups).

${ }^{*} P<0.05$ is considered significant.

Most results with VLDLR II had been obtained, which demonstrate pivotal role of this receptor associated with cellular proliferation and migration. Nakamura et al. reported that VLDLR II is the major receptor in the early phase of fetal brain, which is related to brain development [29]. Furthermore, the studies suggested that VLDLR II and apoE receptor may induce the signal transduction between extracellular Reelin and intracellular Dab1, which phosphorylates Dab1 and activates intracellular kinase to affect the migration and accurate 
A

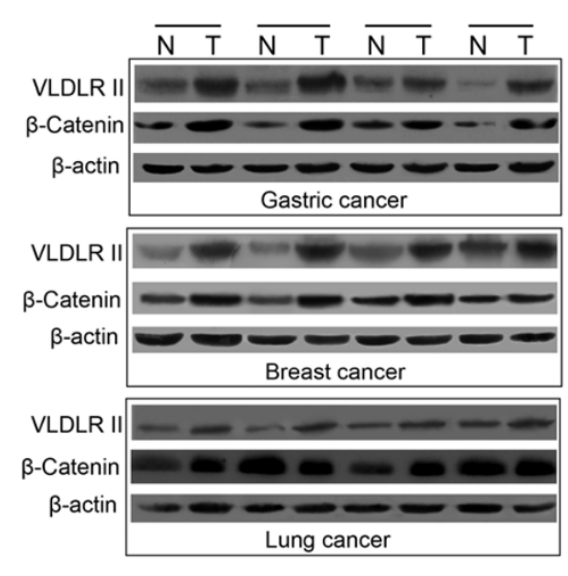

C

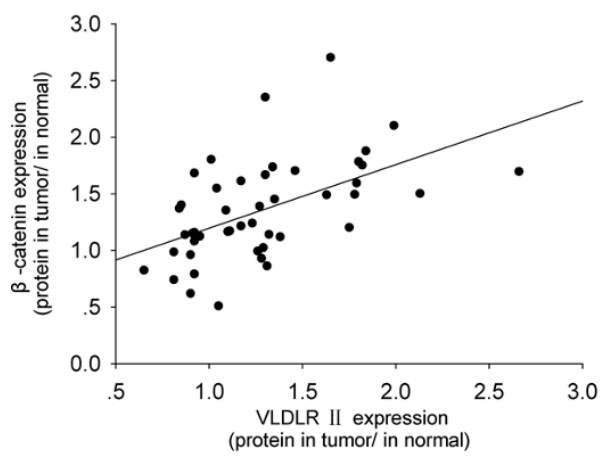

Breast cancer
B

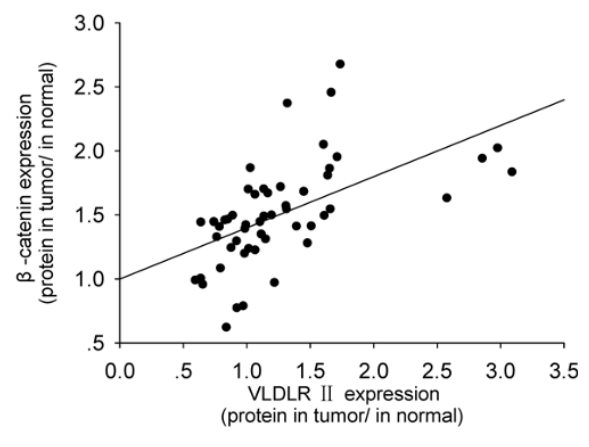

Gastric cancer

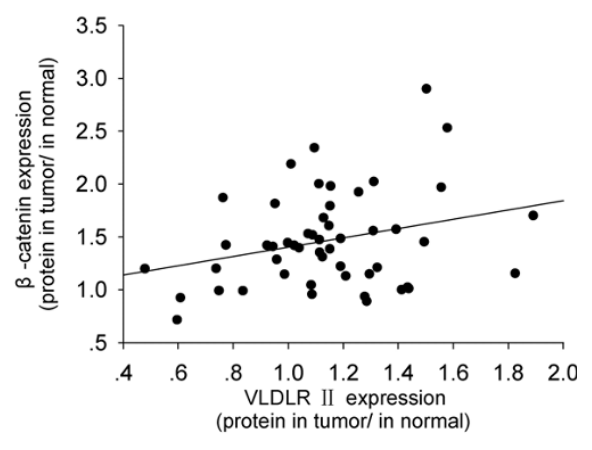

\section{Lung cancer}

Figure 4 Correlation of Western blot expression of VLDLR II with $\beta$-catenin in different cancers. A: Representative Western blot analyses are shown of the VLDLR II and $\beta$-catenin expression in tissues from gastric, breast, and lung cancer patients (4 for each). B-D: Correlation of Western blot expression of VLDLR II with $\beta$-catenin in different cancer tissues. Calculated regression lines also are shown on the correlation plots.

localization of developed neuron, and VLDLR II is the important receptor binding Reelin in developed brain and inducing Reelin signal transduction pathway [30-32]. In addition, Martensen et al. found that VLDLR II expressed by epithelial cancer cells could function in the clearance of cell-surface-associated serine proteinase/serpin complexes in breast carcinomas [33]. We had demonstrated that VLDLR II promotes SGC7901 cell migration and invasion by regulating the expression of matrix metalloproteinase 2 (MMP2) and MMP9 [21]. Recently, we reported that uPA/PAI-1 complex can increase VLDLR expression with promoted cell proliferation and migration and stabilization of $\beta$-catenin [34].

To extend those studies, our interest is to evaluate the relevance of VLDLR II expression with clinical parameters in different human cancer tissues to characterize its role in the cancer transformation progression.

In this research, we studied the expression levels of VLDLR II in a large panel of human cancers and paired normal tissues, since it is reported that VLDLR II is expressed virtually in various cancers [13]. Our present results show that VLDLR II expression in most cancer tissues is higher than the corresponding, adjacent nonaffected control tissues. Specially, VLDLR II expression in breast cancer is highest, followed by gastric and lung cancer.

Patients are also classified on the basis of the most common clinical features of each cancer. Interestingly, some of these parameters correlated with increased VLDLR II expression in cancer samples. For example, 
the higher VLDLR II expression is associated with lymph node metastasis, distant metastasis and advanced TNM stage in breast and gastric cancer tissues. The phenomenon showed that VLDLR II is closely related to the metastasis progression of carcinoma. In breast cancer the presence of negative prognostic markers, such as histological grade, generally correlate with higher VLDLR II expression. In lung cancer, increased VLDLR II expression also correlates with distant metastasis. These results reveal the closer relationship of VLDLR II expression with the clinicopathological guiding, up-regulated VLDLR II expression may represent an clinical marker in some cancers.

$\beta$-catenin is a key effector of the Wnt signaling pathway, which binds members of the T-cell factor (TCF)/ lymphocyte enhancer binding factor (LEF) family of transcription factors and activates target genes transcription to be involved in development, tissue self-renewal and cancer [35]. It also has been reported that VLDLR can regulate the Wnt signaling, which has played an important role in tumorgenesis. Silencing of VLDLR expression by siRNA resulted in increased LRP5/6 levels and $\beta$-catenin phosphorylation in cultured cells [19]. Moreover, we have demonstrated that the $\beta$-catenin levels are associated with VLDLR II expression in the cell culture models, which causes the elevation of $\beta$-catenin levels and promotes cell proliferation and migration through the activation of the $\beta$-catenin/TCF signaling pathway [21]. In this study, we further detected the expression of $\beta$-catenin by Western blot in human cancer samples, the results show that $\beta$-catenin is higher in cancer tissues. Especially, significant positive correlations were found between VLDLR II and $\beta$-catenin in gastric and breast cancers. The data strongly suggest that there is a potential link between VLDLR II and $\beta$-catenin signaling pathway.

In addition, to strengthen the relationship between VLDLR II expression and metastasis, we have conducted a tentative experiment on the expression level of vascular endothelial growth factor (VEGF), which was regarded as a $\beta$-catenin target gene to play a important role in angiogenesis and cancer metastasis progression [36]. We found VLDLR II expression positively correlated with VEGF in breast cancer samples with distant metastasis (data not shown). We would like to carry out more extensive experiment on this topic in order to further intensify the knowledge of the relationship between VLDLR II and cancer progression.

\section{Conclusions}

Together our findings indicate that VLDLR II may be considered as an important role in the metastasis progression of cancers, which is overexpressed in different human cancer types. To our knowledge, this is the first evidence that VLDLR II gets involved in human cancer metastasis at tissue levels. This study will help to thoroughly understand the function of VLDLR II and to open new perspectives for diagnosis and treatment of a wide range of cancers.

\section{Acknowledgements}

We thank Yu Wang, Zhiguo Liu, Jun Sun, and Jianli Guo for their contributions to the article and for simulating discussions. We gratefully thank to the surgeons, pathologists of Tongji Hospital and Union Hospital at Wuhan for the supply of cancer tissues and/or for their assistance in the collection of clinical data. This work was supported by grants from the National Natural Science Foundation of China (No. 30470872, 30300134) and the Doctor Fund Project of Chinese Ministry of Education (No.

20090142110014).

\section{Author details}

${ }^{1}$ Department of Biochemistry and Molecular Biology, Tongji Medical College, Huazhong University of Science and Technology, Wuhan 430030, China. ${ }^{2}$ Clinical Laboratory, Tongji Hospital, Tongji Medical College, Huazhong University of Science and Technology, Wuhan 430030, China. ${ }^{3}$ Department of Thoracic Surgery, Union Hospital, Tongji Medical College, Huazhong University of Science and Technology, Wuhan 430022, China. ${ }^{4}$ Department of Breast and Thyroid Surgery, Tongji Hospital, Tongji Medical College, Huazhong University of Science and Technology, Wuhan 430030, China.

\section{Authors' contributions}

LH designed the study, execution of most experiments, statistical analysis and drafted the manuscript. YJL participated in the design of this study, performed Western blot analysis, image analysis and helped draft the manuscript. PW performed IHC manual analysis and image analysis. JZ and CCY developed the patient database and statistical analysis. SQ proposed this study, organized the research team, interpreted all the data, and writing the manuscript. All authors read and approved the final manuscript.

\section{Competing interests}

The authors declare that they have no competing interests.

Received: 2 August 2010 Accepted: 3 November 2010 Published: 3 November 2010

\section{References}

1. Takahashi S, Kawarabayasi Y, Nakai T, Sakai J, Yamamoto T: Rabbit very low density lipoprotein receptor: a low density lipoprotein receptor-like protein with distinct ligand specificity. Proc Natl Acad Sci 1992, 89:9252-9256.

2. Webb JC, Patel DD, Jones MD, Knight BL, Soutar AK: Characterization and tissue-specific expression of the human 'very low density lipoprotein (VLDL) receptor' mRNA. Hum Mol Genet 1994, 3:531-537.

3. Masuzaki $H$, Jingami $H$, Matsuoka N, Matsuoka N, Nakagawa O, Ogawa $Y$, Mizuno M, Yoshimasa Y, Yamamoto T, Nakao K: Regulation of very-lowdensity Lipoprotein receptor in hypertrophic rat heart. Circ Res 1996, 78:8-14.

4. Takahashi S, Suzuki J, Kohno M, Oida K, Tamai T, Miyabo S, Yamamoto T, Nakai T: Enhancement of the binding of triglyceride-rich lipoproteins to the very low density lipoprotein receptor by apolipoprotein $E$ and lipoprotein lipase. J Biol Chem 1995, 270:15747-15754.

5. Battey FD, Gåfvels ME, FitzGerald DJ, Argraves WS, Chappell DA, Strauss JF Strickland DK: The 39-kDa receptor-associated protein regulates ligand binding by the very low density lipoprotein receptor. J Biol Chem 1994, 269:23268-23273.

6. Mikhailenko I, Krylov D, Argraves KM, Roberts DD, Liau G, Strickland DK: Cellular internalization and degradation of thrombospondin-1 is mediated by the amino-terminal heparin binding domain (HBD). High affinity interaction of dimeric HBD with the low density lipoprotein receptor-related protein. J Biol Chem 1997, 272:6784-6791.

7. Argraves KM, Battey FD, MacCalman CD, McCrae KR, Gåfvels M, Kozarsky KF, Chappell DA, Strauss JF, Strickland DK: The very low density lipoprotein 
receptor mediates the cellular catabolism of lipoprotein lipase and urokinase-plasminogen activator inhibitor type I complexes. J Biol Chem 1995, 270:26550-26557.

8. Kasza A, Petersen HH, Heegaard CW, Oka K, Christensen A, Dubin A, Chan L, Andreasen PA: Specificity of serine proteinase/serpin complex binding to very-low-density lipoprotein receptor and alpha2-macroglobulin receptor/low-density-lipoprotein-receptor-related protein. Eur J Biochem 1997, 248:270-281.

9. Stolt PC, Bock HH: Modulation of lipoprotein receptor functions by intracellular adaptor proteins. Cell Signal 2006, 18:1560-1571.

10. Webb DJ, Nguyen DH, Sankovic M, Gonias SL: The very low density lipoprotein receptor regulates urokinase receptor catabolism and breast cancer cell motility in vitro. J Biol Chem 1999, 274:7412-7420.

11. Andreasen PA, Kjøller L, Christensen L, Duffy MJ: The urokinase-type plasminogen activator system in cancer metastasis: a review. Int J Cancer 1997, 72:1-22.

12. lijima H, Miyazawa M, Sakai J, Magoori K, Ito MR, Suzuki H, Nose M, Kawarabayasi Y, Yamamoto TT: Expression and characterization of a very low density lipoprotein receptor variant lacking the O-linked sugar region generated by alternative splicing. J Biochem 1998, 124:747-755.

13. Nakamura Y, Yamamoto M, Kumamaru E: Very low-density lipoprotein receptor in fetal intestine and gastric adenocarcinoma cells. Arch Pathol Lab Med 2000, 124:119-122.

14. Wada $Y$, Homma $Y$, Nakazato $K$, Ishibashi T, Maruyama Y: Effect of overexpression of very low density lipoprotein receptor on cell growth. Heart Vessels 2000, 15:74-80

15. Ozawa M, Ringwald M, Kemler R: Uvomorulin-catenin complex formation is regulated by a specific domain in the cytoplasmic region of the cell adhesion molecule. Proc Natl Acad Sci 1990, 87:4246-4250.

16. Polakis P: Wnt signaling and cancer. Genes Dev 2000, 14:1837-1851

17. Clements WM, Wang J, Sarnaik A, Kim OJ, MacDonald J, Fenoglio Preiser C, Groden J, Lowy AM: $\beta$-Catenin mutation is a frequent cause of Wnt pathway activation in gastric cancer. Cancer Res 2002, 62:3503-3506.

18. Chen $Y$, Hu Y, Lu K, Flannery JG, Ma JX: Very low density lipoprotein receptor, a negative regulator of the wnt signaling pathway and choroidal neovascularization. J Biol Chem 2007, 282:34420-34428.

19. Nakamura $Y$, Yamamoto $M$, Kumamaru E: Significance of the variant and full-length forms of the very low density lipoprotein receptor in brain. $J$ Brain Res 2001, 922:209-215.

20. Maitra A, Ashfaq R, Gunn CR, Rahman A, Yeo CJ, Sohn TA, Cameron JL, Hruban RH, Wilentz RE: Cyclooxygenase 2 expression in pancreatic adenocarcinoma and pancreatic intraepithelial neoplasia: an immunohistochemical analysis with automated cellular imaging. Am J Clin Pathol 2002, 118:194-201

21. Yang P, Liu Z, Wang H, Tian J, Li Y, Zong Y, Qu S: Enhanced activity of very low density lipoprotein receptor II promotes SGC7901 cell proliferation and migration. Life Sci 2009, 84:402-408.

22. Strickland DK, Gonias SL, Argraves WS: Diverse roles for the LDL receptor family. Trends Endocrinol Metab 2002, 13:66-74.

23. Nykjaer A, Willnow TE: The low-density lipoprotein receptor gene family: a cellular Swiss army Knife? Trends in Cell Biology 2002, 12:273-280

24. Schneider WJ, Nimpf J: LDL receptor relatives at the crossroad of endocytosis and signaling. Cell Mol Life Sci 2003, 60:892-903.

25. Conese M, Nykjaer A, Petersen CM, Cremona O, Pardi R, Andreasen PA Gliemann J, Christensen El, Blasi F: alpha-2 Macroglobulin receptor/Ldl receptor related protein $(\operatorname{Lrp})$ dependent internalization of the urokinase receptor. J Cell Biol 1995, 131:1609-1622.

26. Heegaard CW, Simonsen AC, Oka K, Kjøller L, Christensen A, Madsen B, Ellgaard L, Chan L, Andreasen PA: Very low density lipoprotein receptor binds and mediates endocytosis of urokinase-type plasminogen activator-type-1 plasminogen activator inhibitor complex. J Biol Chem 1995, 27:20855-20861.

27. Webb DJ, Nguyen DH, Sankovic M, Gonias SL: The very low density lipoprotein receptor regulates urokinase receptor catabolism and breast cancer cell motility in vitro. J Biol Chem 1999, 274:7412-7420.

28. Takada H, Imoto I, Tsuda H, Nakanishi Y, Sakakura C, Mitsufuji S, Hirohashi S, Inazawa J: Genomic loss and epigenetic silencing of very-low-density lipoprotein receptor involved in gastric carcinogenesis. Oncogene 2006, 25:6554-6562.
29. Nakamura Y, Yamamoto M, Kumamaru E: A variant very low density lipoprotein receptor lacking 84 base pairs of O-linked sugar domain in the human brain myelin. Brain Res 1998, 793:47-53.

30. Deguchi K, Inoue K, Avila WE, Lopez-Terrada D, Antalffy BA, Quattrocchi CC, Sheldon M, Mikoshiba K, D'Arcangelo G, Armstrong DL: Reelin and disabled-1 expression in developing and mature human cortical neurons. J Neuropathol Exp Neurol 2003, 62:676-684.

31. Homayouni R, Magdaleno S, Keshvara L, Rice DS, Curran T: Interaction of Disabled-1 and the GTPase activating protein Dab2IP in mouse brain. Brain Res Mol Brain Res 2003, 115:121-129.

32. Nakamura Y, Yamamoto M, Kumamaru E: Significance of the variant and full-length forms of the very low density lipoprotein receptor in brain. Brain Res 2001, 922:209-215.

33. Martensen PM, Oka K, Christensen L, Rettenberger PM, Petersen $\mathrm{HH}$, Christensen A, Chan L, Heegaard CW, Andreasen PA: Breast carcinoma epithelial cells express a very low-density lipoprotein receptor variant lacking the O-linked glycosylation domain encoded by exon 16, but with full binding activity for serine proteinase/serpin complexes and $\mathrm{Mr}$ 40,000 receptor-associated protein. Eur J Biochem 1997, 248:583-591.

34. Di Y, Liu Z, Tian J, Zong Y, Yang P, Qu S: TFPI or uPA-PAl-1 complex affect cell function through expression variation of type II very low density lipoprotein receptor. FEBS Lett 2010, 548:3469-3473.

35. Logan CY, Nusse R: The Wnt signaling pathway in development and disease. Annu Rev Cell Dev Biol 2004, 20:781-810.

36. Easwaran V, Lee SH, Inge L, Guo L, Goldbeck C, Garrett E, Wiesmann M, Garcia PD, Fuller JH, Chan V, Randazzo F, Gundel R, Warren RS, Escobedo J, Aukerman SL, Taylor RN, Fantl WJ: beta-Catenin regulates vascular endothelial growth factor expression in colon cancer. Cancer Res 2003, 63:3145-3153.

\section{Pre-publication history}

The pre-publication history for this paper can be accessed here: http://www.biomedcentral.com/1471-2407/10/601/prepub

doi:10.1186/1471-2407-10-601

Cite this article as: He et al:: Up-regulated expression of type II very low density lipoprotein receptor correlates with cancer metastasis and has a potential link to $\beta$-catenin in different cancers. BMC Cancer 2010 10:601.

\section{Submit your next manuscript to BioMed Central and take full advantage of:}

- Convenient online submission

- Thorough peer review

- No space constraints or color figure charges

- Immediate publication on acceptance

- Inclusion in PubMed, CAS, Scopus and Google Scholar

- Research which is freely available for redistribution

Submit your manuscript at www.biomedcentral.com/submit
Biomed Central 